\title{
Value structures among Iranian and British students
}

\author{
Nazanin Abed, Shahla Pakdaman
}

Department of Educational science and Psychology, Shahid Beheshti University of Tehran, Iran

\section{Email address:}

nazanin.abed@yahoo.com (N. Abed), s-pakdaman@sbu.ac.ir (S. Pakdaman)

\section{To cite this article:}

Nazanin Abed, Shahla Pakdaman. Value Structures among Iranian and British Students. Psychology and Behavioral Sciences. Vol. 2, No. 6, 2013, pp. 202-205. doi: 10.11648/j.pbs.20130206.11

\begin{abstract}
Values play a very significant role in individuals' lives. People use their value structure in order to judge the world around them, connecting to other people according to their value priority similarities. People prefer to have relations with those who have similar values as themselves. Schwartz categorizes 10 main values that are comprehensive amongst all cultures. Schwartz believes that the roots of all values stem from these 10 values but the priority of importance varies for different people and various cultures. Considering previous research, the aim of this research is to study the value priorities among Iranian and British university students. 150 Iranian and British university students completed Schwartz's Portrait Values Questionnaire (PVQ). Findings reveal that the priority for Iranian students is Self-direction, Achievement, and Benevolence, with the least important value being Tradition. British students value Self-direction, Benevolence and also Universalism and Achievement at the same level. Much like the Iranian group, they value Tradition least. According to these findings globalization is changing the direction of value transmission from vertical (parents to children) to horizontal (from peers), even in different nations.
\end{abstract}

Keywords: Values, Value Priority, Value change, Value transmission

\section{Introduction}

Values are described as fundamental aspects of human's psychological structure and are apparently common among all humankind. Values are beliefs tied to emotion that have motivational roles in individuals' lives and people try to protect them. Values are also our judgment structure; we decide on people, actions and events according to how well it matches our own values (Schwartz, 2005A). In his previous research, Schwartz categorizes 10 different values; Self-direction, Stimulation, Hedonism, Achievement, Power, Security, Conformity, Tradition, Benevolence and Universalism. His international research on the set of values clarifies that values are comprehensive among all cultures. Although there might be some additional values added to this set in some countries, they are emerged from the 10 main values in Schwartz's model (Schwartz, 2005B; Fischer, Vauclair, Fontaine \& Schwartz, 2010).

Different relations between values can also exist, in that some values oppose each other (e.g. Benevolence and Power) while some others are compatible (e.g. Conformity and Security). People's life circumstances provide opportunities to pursue some of values more easily than other values, For example, wealthy people can pursue Power value more easily compared others (Bardi\&
Goodwin, 2011).

In recent scientific studies of values, two important topics have been discussed which have hardly ever been addressed together; value change and value transmission (Janoff-Bulman, 1989; Chao, 2001).

The term value change mostly deals with societal phenomena. Prominent work in the field emphasize on "modernization" and the overwhelming economic and political forces as the drivers of cultural (Inglehart 1990; 1997; Abramson \&Inglehart, 1995; Inglehart\& Baker, 2000; Gunnoe et. Al., 2006).

Smith, Bond and Kagitcibasi illustrate that increasing contacts between different people from different cultures, may be pushing them towards developing multicultural nations rather than hegemonic monocultural nations (Smith et. al., 2006).

From 1960s many researchers dedicated attention to the term of "modernity". Their focus was mostly upon the imperatives created by the industrialization and urbanization of the society. For example, Kerr and Colleagues believed that the logic of industrialism will eventually lead all the people to a common society, where ideology does not matter anymore (Kerr et. Al, 1960). 
In a research conducted by Inkeles and Smith about "modern" attributes among six nations experiencing economic development (Argentina, Chile, India, Israel, Nigeria and Pakistan), the following attributes were the most common ones. Such as:

Achievement motivation

Individualistic orientation

Independence or self-reliance

Tolerance of and respect for others

Empathetic capacity (Inkeles\& Smith, 1974).

All of the above attributes are somehow related to the 10 main values of Schwartz. Therefore the term value change relates to the social changes that are mostly following modernization, so it may be a normal process to happen among young people as they mostly tend to be more modern and up to date.

The term value transmission usually pertains to the socialization of values in institutions, predominantly in the family (Whitbeck \& Gecas, 1988). It is suggested that in the social and cultural processes of value, value change and value transmission are interrelated but not strictly parallel processes (Boehnke, 2001; Moghaddam \& Cristal, 1997).

Schönpflug suggests that vertical (parent-offspring) and horizontal (peers) transmissions serve more challenging value units. Schönpflug also clarifies that horizontally transmitted values are more beneficial in rapidly changing societies and parent-offspring transmissions do not necessarily support adaptation to different environments. Additionally, it has previously been mentioned that directions of transmission transport different transmission contents (e.g. personality traits and cognitive development by vertical direction, sexual behavior and Conformity by horizontal direction) (Cavalli \& Feldman, 1981). These findings support the fundamentals of our hypothesis; offspring may prefer their peer values in order to adapt to the social environment and therefore their value priorities can differ from their parents' values.

\section{Research Question}

With the above background in mind, the main question of this study is that are the value priorities of Iranian young generation, as an eastern collectivist society, and British young generation, as a western individualist society, different or similar.

\section{Procedure}

The sampling method was simple random sampling, participants were 75 students studying in Shahid Beheshti University of Tehran, Iran and 75 students from Royal Holloway University of London, in Britain. All the participants were young aged, 18 to 25 . The mean age of the Iranian sub sample group was 20.65 years $(\mathrm{Sd}=1.94)$ and 21.06 years for the British sample group $(\mathrm{Sd}=1.75)$.

Values were measured using Schwartz's Portrait Values Questionnaire (PVQ).

\section{Results and Discussion}

The priority for Iranian students is Self-direction, Achievement, and Benevolence, with the least important value being Tradition.

British students value Self-direction, Benevolence and also Universalism and Achievement at the same level. Much like the Iranian group, they value Tradition least.

Table1. Means and ranking of 10 value types for Iranian and British students.

\begin{tabular}{lllll}
\hline Value Types & Iranians & Rank & British & Rank \\
\hline Power & $4.20(1.02)$ & 9 & $3.60(0.82)$ & 9 \\
Achievement & $4.67(0.85)$ & 2 & $4.64(0.77)$ & 3.5 \\
Hedonism & $4.51(0.95)$ & 5 & $4.46(0.85)$ & 5 \\
Stimulation & $4.43(1.00)$ & 7 & $4.27(0.78)$ & 7 \\
Self-direction & $4.99(0.69)$ & 1 & $4.91(0.60)$ & 1 \\
Universalism & $4.47(0.82)$ & 6 & $4.64(0.70)$ & 3.5 \\
Benevolence & $4.62(0.78)$ & 3 & $4.71(0.72)$ & 2 \\
Tradition & $3.39(0.90)$ & 10 & $3.46(0.90)$ & 10 \\
Conformity & $4.34(0.89)$ & 8 & $4.09(0.77)$ & 8 \\
Security & $4.55(0.85)$ & 4 & $4.36(0.69)$ & 6 \\
\hline
\end{tabular}

NOTE: Standard deviations in parentheses.

\section{Conclusion}

According to previous research that shows Iranian and British university students have totally different value priorities compared to their parents (Abed, 2010), and findings of this research that shows value priority of Iranian and British university students are similar, it may be the effect of globalization and modernization that is changing the direction of value transmission from vertical (parents to children) to horizontal (from peers), even in different nations.

People's tend to modernization and globalization is increasing specially in developing countries. As previous research also clarify that different nations (such as Argentina, Chile, India, Israel, Nigeria and Pakistan) with different cultures, value individualistic orientation and selfdirection, respect for others and benevolence, achievement motivation and etc. as their priorities and as the signs of modernization (Ahn, Park \& Kim, 2009; Knafo, 2003).

The study by Boehnke (2001) on value priorities in German university students shows that Self-direction and Achievement have higher means among German students. These findings also prove the fact that in today's global village, despite their different cultures, young generation follow similar value priorities.

According to the fact that Iranians valued achievement as their second priority, but British people valued benevolence on the second, and universalism and achievement as their third priority, it seems that we can observe a reduce in effects of Iranian culture (which values benevolence) in Iran and it can be a topic of interest for 
future research.

Finally, considering the rapid social and cultural change, and personal experiences of new generation about these changes, and also enhancement of between-cultural connections and easier access to worldwide information, joining the global community and being impressed by the peers in international levels, is an unavoidable reality. Therefore, increasing media knowledge and enhancing general information in this area, can prevent the probable side effects for societies.

\section{References}

[1] Abed, N. (2010). Value priorities and well-being. A dissertation for Msc in Applied Social Psychology, Royal Holloway university of London.

[2] Abramson, P. R., \&Inglehart, R. (1995). Value change in global perspective. Ann Arbor: University of Michigan Press.

[3] Ahn, A., J., Park, Y., S. \& Kim, B., S., K. (2009). Asian cultural value gap, cognitive flexibility, coping strategy and parent-child conflicts among Korean Americans. Asian American Journal of Psychology. S(1), 29-44.

[4] Bardi, A., \& Goodwin, R. (2011). The Dual Route to value change: Individual Processes and Cultural Moderators.Journal of Cross-Cultural Psychology.42, 2, 271-287

[5] CavalliBoehnke, K. (2001). Parent-offspring value transmission in a social context: suggestions for a utopian research design. Journal of Cross-Cultural Psychology. 32, 241.

[6] -Sforza, L., L., \& Feldman, M., W. (1981). Cultural transmission and evolution: A quantitative approach. Princeton, NJ: Princeton University Press.

[7] Chao, R., K. (2001). Extending research on the consequences of parenting style for Chinese Americans and European Americans. Child Development, 72, (6), 18321843.

[8] Fischer, R., Vauclair, C.M., Fontaine, R.J.F. \& Schwartz, S. (2010). Are individual-level and country-level value structures different? testingHofstede's legacy with the Schwartz value survey. Journal of cross-cultural psychology. 41 (2), 135-151.

[9] Gunnoe, M., L.,Reiss, D. \& Hetherington, E., M. (2006). Different impact of fathers' authoritarian parenting on early adolescent adjustment in conservative protest versus other families. Journal of Family Psychology. 20(4), 589-596.

[10] Inglehart, R. \& Baker, W., E. (2000). Modernization, cultural change and the persistence of traditional values. American Sociological Reviews, 65, 19-51.

[11] Inglehart, R. (1990). Culture shift in advanced industrial society. Princeton, NJ: Princeton University Press.

[12] Inglehart, R. (1997). Modernization and postmodernization: Cultural, economic, and political change in 43 societies. Princeton, NJ: Princeton University Press.
[13] Inkeles, A., \& Smith, H.D, (1974). Becoming modern: individual change in six developing countries. Cambridge, MA: Harvard University Press.

[14] Janoff-Bulman, R. (1989). Assumptive worlds and the stress of traumatic events: Applications of the schema construct. In A. Bardi\& R. Goodwin (In press). Pathways to value change: A review and proposed mechanisms.

[15] Kerr, C., Dunlop, J.T., Harbison, F.H., \& Myers, C.A. (1960). Industrialism and industrial man. Cambridge, MA: Harvard University Press.

[16] Knafo, A. (2003). Contexts, relationship quality, and family value socialization: The case of parent-school ideological fit in Israel. Personal Relationships, 10, 371-388.

[17] Knafo, A. \& Schwartz, S., H. (2003). Parenting and adolescents' accuracy in perceiving parental values. Child Development, 74, (2), 595-611.

[18] Lowinger, R. J., \& Kwok, H. (2001). Parental overprotection in Asian American children: A psychodynamic clinical perspective. Psychotherapy, 38, 319-330.

[19] Min, P., G. (1995). Asian, Americans: Contemporary trends and issues. Thousand Oaks, CA: Sage, 2nd edition.

[20] Moghaddam, F., M. \& Crystal, D., S. (1997) Revolutions, Samurai, and reductions: The paradoxes of change and continuity in Iran and Japan. Political Psychology, 18, 35584.

[21] Pinquart, M. \&Silbereisen, R., K. (2004). Transmission of values from adolescents to their parents: the role of value content and authoritative parenting. ADOLESCENCE, 39, 153.

[22] Rohner, R. P., \&Pettengill, S. M. (1985). Perceived parental acceptance-rejection and parental control among Korean adolescents. Child Development, 56, 524-528.

[23] Rudy, D. (2001). Implications for understanding the transmission of vlues. Journal of Cross-Cultural Psychology, 32(2), 202-212.

[24] Schonpflug, U. (2001). Culture transmission- A multidisciplinary research field. Journal of Cross-Cultural Psychology, 32, 131-134.

[25] Schwartz, S., H. (1992). Universals in the content and structure of values: theory and imprical tests in 20 countries. In M.P. Zanna (Ed.),Advanced in experimental social psychology (Vol. 25, pp. 1-65).New York: Academic Press.

[26] Schwartz, S. H. (2005a). Basic human values: Their content and structure across countries. In A. Tamayo \& J. B. Porto (Eds.), Valores e comportamentonasorganizaç|Atoes [Values and behaviour in organizations] (pp. 21-55). Petrópolis, Brazil: Vozes.

[27] Schwartz, S., H. (2005b). Robustness and fruitfulness of a theory of universals in individual human values. In A. Tamayo \& J. B. Porto (Eds.), Valores e comportamentonasorganizaçAtoes [Values and behavior in organizations] (pp. 56-95). Petrópolis, Brazil: Vozes

[28] Schwartz, S., H. \&Bardi, A. (2001). Value hierarchies across cultures. Journal of Cross-cultural Psychology, 32(3), 268290. 
[29] Smith, P.B., Bond, M.H. \&Kagitcibasi, C. (2006). Understanding social psychology across cultures. London: Sage.

[30] Tam, K.,P. \& Lee, S., L. (2010). What values do parents want to socialize in their children? The role of perceived normative values. Journal of Cross-Cultural Psychology, 41(2), 175-181.

[31] Whitbeck, L., B. \&Gecas,V. (1988). Value attributions and value transmission between parents and children. Journal of Marriage and the Family. 50, 829-840. 